\title{
Families at risk of colorectal cancer: who are they?
}

\author{
F Kee, B J Collins
}

\begin{abstract}
The first degree kinships of $\mathbf{3 0 5}$ index cases have been studied to determine whether an early age of onset or a particular site distribution characterises familial aggregations of colorectal cancer. The probands comprised 100 patients aged 55-74 years and 205 patients under 55 years at diagnosis and were drawn from a large population database. Ascertainment and verification were complete for 2566 of 2657 first degree relatives. The history of cancer in 296 relatives was validated in $96 \%$ of cases from medical or other records. Among kinships ascertained through index cases under 55 years of age, less than $\mathbf{5 \%}$ had three or more individuals affected by colorectal cancer. The comparable proportion of older probands' families was $3 \%$. Probands with proximal disease were no more likely to have a positive family history of bowel cancer than those with disease distal to the splenic flexure. These findings are consistent with other population based studies of the epidemiology of familial colorectal cancer but contrast with reviews from referral centres and family cancer clinics.
\end{abstract}

Hereditary non-polyposis colorectal cancer (Lynch syndrome) is an apparently autosomal dominant condition characterised by an early age of onset (typically 40-45 years), an excess of proximal tumours and of metachronous disease, and a risk of other malignancies within the pedigree.' Although more common than familial polyposis coli, its prevalence and characteristic features have only rarely been described in population based studies. ${ }^{2-5}$

If multiply affected families are to be recruited for genetic linkage studies or in the evaluation of surveillance programmes for those at highest risk, then ideally these patients should be representative of the general population of susceptibles in the community. Subjects referred to specialist family cancer clinics either because of an early age of onset or a noted familial risk may not reflect the characteristics of the majority of those in the community carrying an inherited susceptibility. ${ }^{6}$

Recently, we estimated the contribution of Lynch syndrome to the total colorectal cancer burden to be between 1 and $2 \%, 5$ a prevalence somewhat less than estimated elsewhere. ${ }^{2+}$ The higher mean age of onset and the absence of a proximal tumour excess gives pause to consider the important differences that can be found between population based studies and those from tertiary referral centres. ${ }^{67}$

We may have underestimated the prevalence of 'cancer families' by restricting family verification to the relatives of probands who were under 55 years of age at diagnosis. Since patients over this age represent most of those seen in general surgical practice, the present study was undertaken to assess the frequency of 'familial' colorectal cancer among the relatives of older probands, to describe the typical age at onset and tumour site distribution, and to compare the findings with those for families of younger probands from the same population.

\section{Methods}

On 1 January 1990, a province wide colorectal cancer register was established at the Queen's University Department of Surgery with the support of all the general surgeons in Northern Ireland. From this source, information was available on all newly diagnosed patients with bowel cancer reported from any of the five histopathology laboratories or 19 acute hospitals serving the province's 1.5 million population.

A consecutive sample of 100 patients aged 5574 years was drawn from the register and within a few months of discharge from hospital each patient was interviewed (with the general practitioner's permission) in his or her own home. From this initial interview, details of the names, addresses, dates of birth and death, and known major illnesses were recorded for all first degree relatives.

A letter was sent to the GPs of all relatives living inside Northern Ireland and confirmation was sought of any bowel disease or malignancy in their patient. If any relative was living outside Northern Ireland they were contacted directly and asked to provide similar details and the names of their general practitioners.

Death certificates were retrieved for deceased relatives. If any relative was reported to have had cancer, this was verified secondarily from hospital notes, histology records, or from cancer registration details.

For comparison, similar details were obtained on the families of 205 colorectal cancer probands under 55 years old, this latter sample representing $95 \%$ of all colorectal cancer patients under 55 years of age at the time of their histological diagnosis during 1976-8.

The $\chi^{2}$ statistic for contingency tables and for testing for linear trend has been calculated by usual methods.

\section{Results}

The 100 consecutively recruited probands were similar in age and tumour site distribution to all the 55-74 year old patients who were registered with the colorectal cancer register during 1990 (Table I). There was some over-representation in the recruited probands of cases in the two older age groups (65-69 years and 70-74 years) but the test for trend was not significant. A similar proportion of these older probands had tumours proximal to the splenic flexure as in the com- 
TABLE I Age $e^{\star}$ and site $\nmid$ distribution of 55-74 year old index cases

\begin{tabular}{lllllll}
\hline & \multicolumn{5}{c}{ Age group (yrs) } & \\
\cline { 2 - 5 } & $55-59$ & $60-64$ & $65-69$ & $70-74$ & Total \\
\hline Interviewed probands & 14 & 24 & 37 & 25 & 100 \\
Probands not recruited & 27 & 38 & 36 & 57 & 158 \\
Total & 41 & 62 & 73 & 82 & 258 \\
\hline \multicolumn{5}{c}{ Site of tumour } & & \\
\cline { 2 - 5 } & Proximal & Distal & & \\
& colon & colon & Rectum & Total \\
\hline Interviewed probands & 37 & 27 & 35 & 100 \\
Probands not recruited & 72 & 42 & 45 & 158 \\
Total & 109 & 69 & 45 & 258 \\
\hline
\end{tabular}

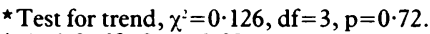

$\mathrm{t} \chi^{2}=1 \cdot 9, \mathrm{df}=2, \mathrm{p}=0 \cdot 39$

parison group of younger patients under 55 years old.

Altogether 846 first degree relatives were reported by the 100 55-74 year old probands The cause of death was verified for 272 of the 296 deceased relatives, and the clinical status of living relatives was established for 525 out of 550 . The overall verification rate $(94 \%)$ was comparable with that reported for the 1811 relatives of the 205 younger probands $98 \%$.

Some 86 relatives of the older probands and 210 relatives of the younger probands were reported to have had cancer and this history was verified in $96 \%$.

Deaths from cancer in first degree relatives (of the older probands) tended to be more accurately reported by index cases than deaths from noncancer causes, though this difference was not significant. The site of their relative's cancer (that is, the principle organ) was identified correctly by the index case in only $57 \%$ of cases. These proportions are very similar to those previously reported for the relatives of the 205 younger probands.

Twenty four relatives of the older probands and 68 relatives of the younger probands had colorectal cancer. Three of the older probands had two or more first degree relatives affected by bowel cancer as compared with 13 of the younger probands. In previous reports these families have been taken to represent probable Lynch syndrome pedigrees.

According to the site of the proband's original tumour (that is, either proximal or distal to the splenic flexure) there was no difference in the proportion of cases with a verified positive family history of colorectal cancer in any first degree relative (Table II).

TABLE II Proportions of young ${ }^{\star}$ and old $†$ probands with a positive family

\begin{tabular}{lllr}
\hline & $\begin{array}{l}\text { Family } \\
\text { history } \\
+v e\end{array}$ & $\begin{array}{l}\text { Family } \\
\text { history } \\
-v e\end{array}$ & Total \\
\hline $\begin{array}{llll}\text { Probands aged less than 55 years: } \\
\quad \text { Index cases with proximal tumour }\end{array}$ & 15 & 30 & 45 \\
$\quad \begin{array}{lll}\text { Index cases with distal tumours } \\
\quad \text { Total }\end{array}$ & 38 & 122 & 160 \\
$\begin{array}{l}\text { Probands aged 55-74 years: } \\
\quad \text { Index cases with proximal tumour }\end{array}$ & 10 & 152 & 205 \\
$\quad \begin{array}{lll}\text { Index cases with distal tumours } \\
\text { Total }\end{array}$ & 11 & 52 & 37 \\
& 21 & 79 & 100 \\
\hline
\end{tabular}

${ }^{\star} \chi^{2}=1 \cdot 22, \mathrm{df}=1, \mathrm{p}=0 \cdot 27$

$+\chi^{2}=0.77, \mathrm{df}=1, \mathrm{p}=0.38$
TABLE III Site distribution of bowel tumours in first degree relatives

\begin{tabular}{llrlll}
\hline & $\begin{array}{l}\text { Proximal } \\
\text { colon }\end{array}$ & $\begin{array}{l}\text { Distal } \\
\text { colon }\end{array}$ & Rectum & $\begin{array}{l}\text { Colon } \\
\text { unspecified }\end{array}$ & Total \\
\hline $\begin{array}{l}\text { Relatives of } \\
\begin{array}{l}\text { young probands } \\
\text { Relatives of } \\
\text { old probands }\end{array}\end{array}$ & 17 & 18 & 14 & 19 & 68 \\
\begin{tabular}{l} 
Total \\
\hline
\end{tabular} & 21 & 24 & 20 & 27 & 92 \\
\hline
\end{tabular}

$\chi^{2}=0 \cdot 89, \mathrm{df}=3, \mathrm{p}=0 \cdot 83$

The site distribution of bowel tumours in relatives of old and young probands is given in Table III. No significant difference is apparent $\left(\chi^{2}=0 \cdot 89, \mathrm{df}=1, \mathrm{p}=0 \cdot 82\right)$.

\section{Discussion}

Over the past 20 years, Lynch has documented numerous meticulously verified families that exhibit an autosomal dominant tendency to early onset colorectal cancer, an excess of proximal tumours and of metachronous disease, and a high risk of other malignancies in the pedigree. These classic features have been well described in families from other countries, ${ }^{9}$ and in studying them there is undoubtedly much to learn about the origins of susceptibility to colorectal cancer. Screening these families would probably have only a modest impact on the population's mortality from colorectal cancer, and though the benefits to the families might be greater, a thorough evaluation of such a policy is still awaited.

It is important, nonetheless, that these families are readily and correctly identified in normal surgical practice if a scarce resource like colonoscopy is to be targeted to those most likely to benefit. Recognising the importance of estimating the contribution of Lynch syndrome to the overall colorectal cancer burden, Mecklin pragmatically defined affected families if there were three or more kin with colorectal cancer in a first degree kinship. He was not convinced that there were sufficient grounds to subdivide the syndrome. ${ }^{2}$ Despite the potential for environmentally determined penetrance, and differing competing risks and family sizes in different communities, he did not consider that its frequency would vary between countries.

Until a valid biomarker for susceptibility is available, the surgeon can only delineate those most at risk by relying on clinical pointers such as the age at onset, the site of the tumour, and the index case's family history. Proximal colonic neoplasms have not invariably been associated with significant familial aggregation ${ }^{610}$ and the evidence for an association with early age at onset is similarly diverse. ${ }^{311}$ Data accrued at tertiary referral centres may be less applicable to the work of the average surgeon and can be distorted by ascertainment bias. This is often treated superficially. A recent study recruited probands because they had been referred to a family cancer clinic by either their general practitioner or their relatives but still declared that the analysis was 'designed to estimate the risks of cancer among first degree relatives in order to warn surgeons of the need to institute screening programmes for 
first degree relatives of young patients with breast and colon cancer.

Northern Ireland provides fertile soil for population based studies of familial cancer. Mortality from colon cancer is high; families tend to be larger and more cohesive than in the rest of the United Kingdom; and demographically the population is much more homogeneous. ${ }^{12}$ The present study has attempted to describe whether distinctive features characterise familial aggregations of colorectal cancer ascertained without regard to family history from a large population database.

Our study could be criticised in that the sampling of index cases aged 55-74 years was not strictly random. Instead, a consecutive sample of 100 patients was interviewed after discharge from hospital, providing permission was given by the general practitioner. Of the 20 patients not consecutively recruited, 19 were terminally ill and died shortly after discharge from hospital However, we have not previously found any association between survival and 'familiality,' and the non-participation of these subjects should not bias our conclusions. ${ }^{13}$ The age at diagnosis and bowel site distribution of interviewed patients were comparable with those of all cases that were finally registered by year end, and we have no reason to believe that the sample was unrepresentative. (In no case where permission was refused did the clinical records of these patients indicate any familial risk). The comparison group of young probands was retrospectively drawn and represented $95 \%$ of all such index cases diagnosed during 1976-8. Although the age distributions of the two groups of relatives are not identical, drawing a retrospective example allowed a significant proportion of the first degree relatives to have reached the reported age of greatest risk.

In only $57 \%$ of cases was the organ affected by cancer correctly identified by a first degree relative and studies that indicate that the history was verified only 'where possible' should be interpreted cautiously.

Patients aged between 55 and 74 years are nearly three times more common than those under 55 at diagnosis and represented $53 \%$ of all patients registered during 1990 . If $3 \%$ of these index cases have significant familial aggregations of colorectal cancer (fulfilling Mecklin's pragmatic definition of Lynch syndrome), then based on the contribution that these probands make to the overall tumour burden, it is probable that these families are at least as numerous in the community as those ascertained through early onset cases. Although the average age at onset in relatives of older probands was significantly greater than among the relatives of the younger cases, no study conducted at a single point in time can realistically assess a family's lifetime cancer risk. Nevertheless, our results are in keeping with those from two other large population based studies, each with a sample size of over 1500 index cases. ${ }^{6} 10$

A characteristic age at onset among individuals carrying a supposed inherited susceptibility is not reliably estimated from the mean of affected individuals in a family, though this is how it has more usually been described. Variable lead time from ascertainment bias and the inability to distinguish between sporadic and genetic cases probably contributes to the heterogeneity in the observed age at onset distributions in 'cancer families.' More valid estimations have recently been made using life table methods. ${ }^{14}$ Likewise, any pragmatic syndrome definition based on case 'counts' can be subject to similar sorts of criticism.

In this study probands with proximal tumours were no more likely to have a verified positive family history of colorectal cancer than those with disease distal to the splenic flexure, and the site distribution of bowel cancers in the relatives of young probands did not significantly differ from the distribution among relatives of older index cases. These findings run counter to the suggestion that young patients and those with proximal tumours are more likely to come from high risk pedigrees. ${ }^{15}$

An alternative interpretation might be that our study lacks statistical power to detect a true difference in the 'positive family history rate' of older and younger probands. However, this is one of the largest studies of its kind reported in the United Kingdom and the findings are consistent with several larger population based studies. ${ }^{6}{ }^{10}$

Most of the affected relatives for whom the site within the colon was unspecified were validated from death certificates. For this to have seriously biased our comparison, one would have to conclude that the underspecification of tumour site on death certificates was differentially related to the presence of familial aggregation of cancer among young or older relatives. On the contrary, from necropsy studies there is evidence that proximal tumours in older patients are more likely than distal cancers to be underdiagnosed before death. ${ }^{16}$

Our study could also be criticised for not evaluating any potential association between proximal or early onset colorectal cancer and the risk of other types of cancer in the kinship. It is indeed possible that some families at high risk of bowel cancer might be ascertained through the aggregation of other malignancies with the pedigree. ${ }^{7}$ While the concurrence of multiple types of tumours has been clearly described by Lynch, the potential for genetic heterogeneity will make the formulation of rational screening strategies difficult. Although the need for a biomarker is self evident, appraising the performance of a 'marker' (its sensitivity, specificity, and predictive power) will be difficult without a focus on a unitary syndrome. ${ }^{17}$

Screening recommendations must be guarded until the underlying genetic mechanisms are clarified. For instance, by calculating a crude segregation ratio using 'affected by any cancer' as the numerator, one recent study found that the value approximated that expected for an autosomal dominant trait and thus supported the authors' contention that a group of true 'cancer families' had been ascertained. ${ }^{3}$ This, despite the fact that in Lynch's largest formal segregation analysis (of 11 families and 2762 individuals) there was significant departure from all Mendelian and environmental hypotheses when cancers at all sites were considered to be pleiotropic effects of the same gene. ${ }^{18}$ 
Though not proved, there is every likelihood that a number of high risk families with the classic features of Lynch syndrome might benefit from regular colonoscopic surveillance. However, many districts in the UK can barely support a full diagnostic colonoscopy service ${ }^{19}$ and it is important that surgeons can identify those most at risk. This study had demonstrated that: (i) familial aggregation of colorectal cancer may be as frequent in the community among patients aged 55-74 years as among those under this age and (ii) a proximal site predilection is not characteristic of most such family clusters. Identifying the high risk pedigrees (that are likely to benefit most from screening) is vital, but there remains much to be learned about the natural history of bowel cancer in these families. It might be salutary to conclude by echoing Lynch's own cautionary note:

'Needless to say it is difficult to be certain whether a homogeneous entity is being studied and difficult to determine what proportion of the study subjects at risk for hereditary non-polyposis colorectal cancer have a common familial or genetic susceptibility to adenoma formation unrelated to NHPCC. The interpretation of our results . . . in patients with HNPCC was limited by an inability to obtain tissue from patients who were definitely affected by the disease.' ${ }^{20}$

The authors are grateful to Mr John Moorehead FRCS, Director of the Northern Ireland Colorectal Cancer Register, for granting access to the database. Thanks are also due to Mrs Ann Kay for assistance with pedigree verification.

This work was supported by a grant from the Ulster Cancer Foundation.

1 Lynch HT, Kimberling WJ, Albano Wa, Scheulke GS, Lynch $\mathrm{JF}$, Biscorie KA, et al. Hereditary non-polyposis colorectal cancer, Parts I and II. Cancer 1985; 56: 939-51.
2 Mecklin JP. Frequency of hereditary colorectal carcinoma. Gastroenterology 1987; 56: 1021-5.

3 Ponz de Leon M, Sasseteli R, Sachetti C, Zanghieri G, Scalmati A, Roncucci L, et al. Familial aggregation of tumors in the three year experience of a population based colorectal cancer registry. Cancer Res 1989; 49: 4344-8.

4 Fisher G, Armstrong B. Familial colorectal cancer and the screening of family members. Med $\mathcal{F}$ A ust $1989 ; 150: 22-5$.

$5 \mathrm{Kee} F$, Collins B. How prevalent is cancer family syndrome? Gut 1991; 32: 509-12.

6 Cannon-Albright LA, Thomas TC, Bishop T, Skolnick MH, Burt RW. Characteristics of familial colon cancer in a large population data base. Cancer 1989; 64: 1971-5.

7 Itoh H, Houlston RS, Harocopos C, Slack J. Risk of cancer death in first degree relatives of patients with hereditary nondeath in first degree relatives of patients with hereditary non-
polyposis cancer syndrome (Lynch type II): a study of 130 polyposis cancer syndrome (Lynch type II): a study of 130
kindreds in the United Kingdom. Br f Surg 1991; 77: kindreds

8 Armitage P, Berry G. Statistical methods in medical research. 2nd ed. Oxford: Blackwell, 1987.

9 Sarroca C, Quadrelli R, Praderi R. Cancer colique familial. Nouv Presse Med 1978; 7: 1412 .

10 Sondergaard J, Bulow S, Lynge E. Cancer incidence among parents of patients with colorectal cancer. Int $\mathcal{f}$ Cancer 1991 ; 47: 202-6.

11 Schneider NR, Chaganti SR, German J, Chaganti RSK. Familial predisposition to cancer and age at onset of disease in randomly selected cancer patients. Am F Hum Genet 1983; in random: $454-67$.

12 Demographic trends in Northern Ireland. 1986. Belfast, Northern Ireland Economic Council Report 57.

13 Kee F, Collins BJ. Histological characteristics and outcome of familial non-polyposis colorectal cancer. Scand 7 Gastroenterol 1991; 26: 419-24.

14 Chidambaram A, Chakravarti A, Ferrell RE, Iyengar S. Estimating the age at onset function using life-time methods. Genet Epidemiol 1988; 5: 255-63.

15 Lynch HT, Watson PW, Kreigler M, Lynch JF, Lanspa SJ, Marcus J, et al. Differential diagnosis of hereditary nonpolyposis colorectal cancer. Dis Colon Rectum 1988; 31: 372-7.

16 Delendi M, Gardiman D, Riboli E, Sasco A. Latent colorectal cancer found at necropsy. Lancet 1989; ii: 1331-2.

17 Schulte PA. Methodological issues in the use of biologic markers in epidemiologic research. Am $\mathcal{F}$ Epidemiol 1987; markers in epide $1006-17$.

18 Bailey-Wilson J, Elston RC, Scheulke GS, Kimberling W, Albano WA, Lynch JF, et al. Segregation analysis of hereditary non-polyposis colorectal cancer. Genet Epidemiol 1986; 3: 27-38.

19 Report of the Endoscopic Section of the British Society of Gastroenterology. Future requirements for colonoscopy in Britain. Gut 1987; 28: 772-5.

20 Sams JS, Lynch HT, Burt R, Lanspa SJ, Boland CR, et al. Abnormalities of lectin histochemistry in familial polyposis coli and hereditary non-polyposis colorectal cancer. Cancer 1990; 66: 502-8. 